\title{
MODIFICAÇÕES COMPORTAMENTAIS ENTRE O PRÉ E O PÓS-OPERATÓRIO DE PACIENTES BARIÁTRICOS
}

\author{
BARIATRIC PATIENTS' BEHAVIORAL CHANGES BETWEEN PREOPERATIVE AND \\ POSTOPERATIVE STAGES
}

LOS CAMBIOS DE COMPORTAMIENTO ENTRE EL PRE Y EL POST-OPERATORIO DE PACIENTES BARIÁTRICOS

\author{
Yara Alves Costa Justino* \\ Tainá Moreira Bolelli Tatagiba \\ Linea Picolli Pogian ${ }^{* * *}$ \\ Felipe de Carvalho Pimentel ${ }^{* * *}$
}

\begin{abstract}
RESUMO
Esta pesquisa buscou conhecer as mudanças no comportamento alimentar do paciente bariátrico, analisando a função desse repertório antes e depois da cirurgia. Investigou-se também o processo de avaliação psicológica préoperatória, o acompanhamento terapêutico realizado nesse contexto bem como a existência ou não de repertórios alternativos ao comportamento alimentar que auxiliem no manejo do pós-cirúrgico. Os dados foram coletados em entrevistas semiestruturadas com 15 pessoas que realizaram a cirurgia. Os resultados indicaram que, antes do procedimento, o alimentarse era primordialmente mantido por reforço negativo, mas também por reforço positivo. Contudo o relato do pós-cirúrgico mostrou poucas alterações na função desse comportamento bem como a inexistência de repertórios alternativos, indicando probabilidade aumentada de, em longo prazo, de os sujeitos retornarem ao seu padrão nutricional anterior e viverem a reengorda. Em relação à avaliação psicológica e ao acompanhamento terapêutico, verificaram-se esses processos como pouco efetivos entre os procedimentos pré e pós-operatórios.
\end{abstract}

Palavras-chave: Cirurgia bariátrica. Análise funcional do alimentar-se. Repertório alternativo para produzir reforçadores. Avaliação psicológica pré-cirúrgica. Acompanhamento terapêutico.

Texto recebido em 25 de fevereiro de 2015 e aprovado para publicação em 19 de novembro de 2015 .

"Mestranda no Programa de Pós-Graduação em Psicologia na Universidade Federal do Espírito Santo (UFES), graduada em Psicologia pela Faculdade Católica Salesiana do Espírito Santo.E-mail: yarajustino@hotmail.com.

**Pós-graduanda em Geriatria e Gerontologia na Universidade Veiga de Almeida, graduada em Psicologia pela Faculdade Católica Salesiana do Espírito Santo.E-mail: taina.tatagiba@hotmail.com.

***Graduada em Psicologia pela Faculdade Católica Salesiana do Espírito Santo, residente em Atenção ao Câncer no Hospital Evangélico de Cachoeiro de Itapemirim-ES, Brasil.E-mail: lineapicoli@yahoo.com.br.

**** Mestre em Psicologia pela UFES, especialista em Psicoterapia Comportamental pelo Instituto de Terapia por Contingências em Campinas-SP, Brasil. E-mail: felipecpimentel@hotmail.com. 


\begin{abstract}
This research aimed to know the changes in a bariatric patient's feeding behavior, analyzing the function of this repertoire before and after surgery. It also investigated the process of preoperative psychological evaluation, therapeutic monitoring conducted in this context, and the existence or lack of existence of alternative options for eating behavior which help to assist in the management of post-surgical period. Data were collected from semistructured interviews with fifteen people who underwent the surgery. The results indicated that before the procedure, the food itself was primarily maintained by both, negative and positive reinforcement. However, the reporting on post-surgical stage showed little change in the function of this behavior, as well as the absence of alternative options, indicating increasing likelihood of subjects returning, in a long run, to their previous nutritional status, and regaining lost weight. Psychological assessment and therapeutic monitoring processes proved to be ineffective in between preoperative and postoperative procedures.
\end{abstract}

Keywords: Bariatric surgery. Functional analysis of feeding. Alternative repertoire to produce boosters. Pre-surgical psychological evaluation. Therapeutic monitoring.

\title{
RESUMEN
}

Esta investigación tuvo como objetivo conocer los cambios en el comportamiento alimentario del paciente bariátrico, analizando la función de este repertorio antes y después de la cirugía. También se investigó el proceso de evaluación psicológica preoperatoria, el seguimiento terapéutico realizado en este contexto, así como la existencia de repertorios alternativos para la conducta alimentaria que ayuden en el acompañamiento post quirúrgico. Los datos se obtuvieron de entrevistas semi-estructuradas con quince personas que se sometieron a cirugía. Los resultados indicaron que antes del procedimiento, el hecho de alimentarse se mantuvo principalmente por el refuerzo negativo, pero también por el refuerzo positivo. Sin embargo, el informe post quirúrgico mostró pocos cambios en la función de este comportamiento, y la ausencia de repertorios alternativos, lo que indica una mayor probabilidad de que a largo plazo, los sujetos vuelvan a su estado nutricional previo y experimenten aumento de peso. En cuanto a la evaluación psicológica y al seguimiento terapéutico, se observaron estos procesos como ineficaces entre el pre y el post-operatorio.

Palabras clave: Cirugía bariátrica. Análisis funcional de la alimentación. Repertorio alternativo para producir refuerzos. Evaluación psicológica previa a la cirugía. Seguimiento terapéutico. 


\section{INTRODUÇÃO}

obesidade é um problema mundial de saúde pública e que tem sido A discutida nos meios científicos, na busca de novas estratégias de prevenção 1 e combate. Francischi, Pereira, Freitas, Klopfer, Santos, Vieira e Lancha Júnior (2000) discutem que o novo padrão de comportamento alimentar adotado nas últimas décadas, composto por um alto consumo de calorias e de baixo valor nutricional, aliado à diminuição progressiva de atividades físicas, tem contribuído, de forma relevante, para o aumento do número de casos de obesidade em todo o mundo. De acordo com dados da Organização Mundial da Saúde (World Health Organization [WHO], 2012), 65\% da população mundial vivem em países onde o sobrepeso e a obesidade mata mais que a desnutrição, sendo esta apontada como o quinto maior fator de risco de morte global. Dados da mesma organização indicam que 44\% dos casos de diabetes, $23 \%$ dos casos de doenças isquêmicas do coração e entre $7 \%$ e $41 \%$ dos encargos de câncer estão relacionados à obesidade. Além disso, verifica-se que esse fenômeno, como estigmatizador, produz discriminação, preconceito e exclusão social (Fellipe, 2003), comprometendo também a saúde psicológica e o comportamento social da pessoa.

Assim, considerando os vários aspectos relacionados ao fenômeno da obesidade, algumas pessoas começam a buscar por diferentes tipos de tratamento que reduzam o excesso de peso e, possivelmente, devolva a elas uma vida mais ativa, saudável e com mais qualidade. Entre essas soluções, destacam-se dietas, exercícios físicos e medicações que auxiliam na redução do peso, inibição do apetite ou mesmo os ansiolíticos.

Contudo, mesmo a partir dos tratamentos supracitados, muitas vezes, o obeso não alcança o emagrecimento desejado, e assim a cirurgia bariátrica se mostra uma alternativa atrativa para redução do excesso de peso. Isto é, os pacientes que não respondem às manobras terapêuticas mais comuns acabam necessitando de uma intervenção mais severa (Fandiño, Benchiolmol, Coutinho \& Appolinário, 2004). Desse modo, a cirurgia bariátrica tem se mostrado uma técnica importante na condução clínica de alguns casos de obesidade.

A intervenção cirúrgica bariátrica é composta por algumas técnicas com respaldo científico, indicada apenas para pessoas com índice de massa corporal (IMC) acima de $40 \mathrm{~kg} / \mathrm{m}^{2}$ (independentemente da presença de comorbidades); IMC entre 35 e $40 \mathrm{~kg} / \mathrm{m}^{2}$ (na presença de comorbidades) e IMC entre 30 e $35 \mathrm{~kg} / \mathrm{m}^{2}$ (na presença de comorbidades que tenham obrigatoriamente a classificação grave por um médico especialista na respectiva área da doença) (Sociedade Brasileira de Cirurgia Bariátrica e Metabólica [SBCBM], 2013). 
Além disso, os candidatos à cirurgia devem passar pelo tempo mínimo de cinco anos de evolução da obesidade e história de falência dos tratamentos citados (Ehrenbrink, Pinto \& Prando, 2009).

Verifica-se que, ao realizar o procedimento, muitos resultados são esperados pelos pacientes candidatos à cirurgia, como perda de peso, melhora na qualidade de vida e com relação às comorbidades associadas à obesidade (Moliner \& Rabuske, 2008). Entretanto se verifica que não há uma reflexão sobre as diferentes variáveis que envolvem o procedimento e a complexidade da intervenção, sobretudo no que tange à necessidade de mudanças drásticas nos hábitos sociais e comportamentais do sujeito, com relação à sua autoimagem, autoestima, autoconfiança e, em especial, seu comportamento alimentar. Isto é, considerando a função do alimentar-se para o paciente que, na maioria das vezes, vai além das necessidades energéticas do organismo, mas, sobretudo, utilizado como estratégia de controle emocional (Vale \& Elias, 2011; Quaglia apud Cardoso, Costa, Menezes, Magalhães \& Pires, 2004), ao realizar a cirurgia, verifica-se que o sujeito estará fisiologicamente impedido de manter seu comportamento alimentar hipercalórico. Assim, fazem-se necessários repertórios alternativos para lidar com a nova contingência e alcançar os reforçadores que, outrora, eram obtidos por meio do comportamento alimentar.

Tendo em vista esses aspectos, esta pesquisa teve como objetivo discutir a função do alimentar-se na vida do sujeito antes da intervenção, bem como investigar a forma como esse comportamento é manejado no pós-cirúrgico e a existência ou não de novos repertórios e, ou, repertórios alternativos para lidar com as contingências depois de operado. Também foram investigados os processos de avaliação psicológica pré-operatória e acompanhamento terapêutico nesse contexto.

Para isso, este trabalho foi dividido em dois momentos, baseados em cinco tópicos com os principais eixos verificados durante a análise de dados. Em um primeiro momento, a partir da literatura e do relato dos entrevistados, foram analisados aspectos referentes ao período anterior à intervenção, tais como reforço, comportamento alimentar e obesidade, as operaçôes estabelecedoras para realização da cirurgia e a avaliação psicológica para realização da cirurgia. Depois, em um segundo momento, discutiram-se os principais resultados referentes aos objetivos da pesquisa, tais como as novas regras alimentares no pós-cirúrgico e repertórios alternativos. Por fim, analisaram-se as possíveis e prováveis consequências da falta de acompanhamento psicológico durante esse processo. 


\section{MÉTODO}

Esta pesquisa foi realizada de acordo com um delineamento exploratório, de cunho qualitativo. Tendo em vista tal metodologia, foram entrevistados 15 sujeitos que se submeteram ao procedimento cirúrgico bariátrico. Os sujeitos foram escolhidos pelo procedimento de amostragem por conveniência e acessibilidade, considerando o tempo mínimo de operado de seis meses. Tal período foi escolhido, pois foi verificado que, a partir dessa fase, o paciente, em geral, inicia seu processo de reabilitação do pós-cirúrgico e então se expõe a situações sociais, contexto que proporciona melhor discriminação aos entrevistados das situações propostas para descrição durante as conversas.

Para realização das entrevistas, foi elaborado um roteiro semiestruturado, que norteou a conversa entre entrevistado e entrevistador. Esse roteiro foi dividido em dois blocos. O primeiro foi construído de modo a pesquisar como eram os comportamentos dos sujeitos antes da intervenção cirúrgica bariátrica, isto é, como era a sua alimentação, quais eram os sentimentos antecedentes de seu comportamento alimentar, como era sua vida social antes da cirurgia, se o sujeito fazia ingestão de bebidas alcoólicas (e outras drogas) e o motivo pelo qual ele optou pela intervenção bariátrica. No segundo bloco das entrevistas, foram investigados dados do pós-operatório, isto é, como se estabeleceu a alimentação do sujeito depois da intervenção cirúrgica, como ele lida com a restrição alimentar, como ele descreve a ingestão de bebidas alcoólicas (e outras drogas) no pós-operatório e se houve mudança na sua vida social.

\section{RESULTADOS E DISCUSSÃO}

\subsection{Reforço, comportamento alimentar e obesidade}

Partindo da perspectiva teórica da análise do comportamento, ciência fundamentada na filosofia do behaviorismo radical, que defende a ideia da multideterminação comportamental dos organismos, identificar as relaçōes funcionais entre padróes comportamentais e variáveis ambientais, mediante o exame das contingências presentes, faz-se relevante visto que pode auxiliar o psicólogo a entender alguns comportamentos e sentimentos do cliente obeso que busca pela intervenção cirúrgica bariátrica (Skinner, 2000).

Nesse sentido, para que se possa discutir sobre a obesidade, torna-se fundamental entender a função do comportamento alimentar na vida do sujeito bem como as diferentes variáveis atreladas a ele. Dessa forma, faz-se necessário explicitar as relações entre o reforço e o comportamento alimentar. 
O reforço é o princípio fundamental do comportamento operante e um dos princípios mais aplicados na análise do comportamento (Vollmer \& Hackenberg apud Vieira, 2006). Ele descreve o aumento da probabilidade futura de um operante que foi sucedido por um estímulo. Portanto reforçadores podem ser definidos pelo seu efeito em elevar a taxa de um comportamento operante futuramente.

De modo geral, os estímulos se deslocam ao longo de um contínuo, exercendo diferentes funções de acordo com o contexto, a história de vida e os níveis de privação e saciedade do organismo. Assim, os sujeitos podem ter seu comportamento reforçado de forma positiva ou negativa e, de qualquer modo, a consequência será sempre a mesma: o aumento da frequência de um dado comportamento. A partir disso, discute-se a função reforçadora positiva que o alimento exerce na vida do sujeito obeso. Isto é, o esquema de reforço positivo é usado para aumentar a probabilidade futura da resposta que o produz, acrescentando-se um estímulo agradável ao ambiente do sujeito (Martin \& Pear, 2009). Assim como descrito por alguns participantes, quando eram reforçados com o sabor prazeroso dos alimentos, aumentando a probabilidade futura de eles voltarem a se comportar. Os relatos são didáticos:

Eu só queria saber de comer molho branco, macarrão, lasanha, chocolate, doce, pão, pizza. Só essas coisas assim, gostosas. [...] Eu amo comer (Sandra).

Eu pegava uma coisa e não conseguia parar de comer... Tinha que comer assim, até não caber mais. [...] Tanto que eu nem fazia muita coisa em casa, porque se eu fizesse um bolo, eu queria comer o bolo inteiro (Simone).

Eu comia direto, eu comia muito doce. Eu era viciada no doce, comia demais. [...] Aquilo eram potes e potes de doce de leite que eu comia, entendeu? (Elisa).

Para melhor entender a relação entre o reforço e o comportamento alimentar aqui apresentado, também vale destacar a definição de Skinner (2000) sobre os reforçadores incondicionados. Segundo o autor behaviorista, os reforçadores incondicionados dizem respeito a uma classe de eventos, cujo poder de aumentar a probabilidade do comportamento se constituiu a partir da história filogenética de determinada espécie. Isto é, a história evolutiva da espécie humana aponta para a existência de um ambiente precário, com pouca disponibilidade de alimentos. Pontua-se que nossos ancestrais sobreviviam basicamente da coleta de frutas, grãos e da caça, por mecanismos rudimentares (A. Netto, 2002). Seguindo o mesmo autor, acredita-se que aqueles organismos eficazes no armazenamento de energia sobreviviam. 
Assim, considerando o valor de sobrevivência do alimento na história de seleção natural da espécie, Vale e Elias (2011) discutem, partindo de Skinner, a sensibilidade inata ao alimento como reforçador. Tal sensibilidade biológica relaciona-se à eliciação de respondentes de sensações de prazer ao se ingerirem os alimentos. Os autores ainda destacam as diferentes sensações, de acordo com a ingestão também diferenciada de alimentos. Nesse sentido, alimentos como açúcares, carboidratos e gorduras, por terem sido úteis na história de sobrevivência da espécie, tornaram-se mais capazes que outros grupos de alimentos, tais como verduras e vegetais na eliciação sensações prazerosas. Desse modo, a literatura aponta que os sujeitos têm maior propensão à compulsão alimentar, a partir de alimentos hipercalóricos. O que também foi possível identificar durante a pesquisa, pelos relatos das entrevistadas:

Eu gostava de estar comendo. Num é arroz e feijão. É lanche, doces, biscoitos, massas, hambúrguer, cachorro-quente... Eu sou apaixonada por cachorro-quente (Diana).

Adorava besteiras do tipo chips, chocolate... Chocolate é uma coisa que eu gosto muito, até hoje é difícil controlar. E bastante massa. Eu acordava, tomava café, comia pão. Aí, almoçava, comia uma lasanha. Aí tomava café da tarde, comia pão de novo. Aí jantava e comia uma macarronada (Sonia).

Eu gostava de comidas calóricas. Eu gostava de feijoada, torresmo [...]. Tudo... Tudo o que não pode, hoje, eu comia antes. [...] Era bala, refrigerante, biscoito, bolo... Eu era viciada em Coca-Cola. Meu café da manhã era Coca-Cola. [...] Chocolate, doce, salgado (Karina).

No que tange ao reforço negativo, primordialmente citado no relato dos sujeitos durante as entrevistas, analisa-se que sua incidência também aumenta a probabilidade de um comportamento. Entretanto, este se constitui da retirada de um estímulo aversivo (que cause desprazer) do ambiente. Nesse sentido, considerando um dos objetivos da pesquisa, isto é, identificar a função do alimentar-se na vida do sujeito, analisaram-se, no relato dos entrevistados, os antecedentes desse comportamento.

De acordo com os dados anteriormente revisados na literatura, por meio do esquema de reforço negativo, a comida pode ser um dispositivo para fugir do contato com emoções aversivas, propiciando contato com reforçadores positivos, o alimento e as sensações produzidas por ele (Vale \& Elias, 2011). Nesse sentido, os autores argumentam, partindo de Meyer (2008), que os episódios de hiperfagia estão relacionados, em geral, à liberação de opioides endógenos, neurotransmissores ligados à regulação da ansiedade, humor e mediação das sensações de prazer. De acordo com tal afirmação, analisa-se que, ao comer, respondentes reforçadores são eliciados, diminuindo-se a sensação desagradável produzida pelas situações aversivas em que o sujeito possua déficit de repertório 
ou repertório pouco desenvolvido para lidar, bem como explicando a manutenção desse repertório de fuga-esquiva ligado à comida.

Assim, considerando a possibilidade de uma mesma análise, de acordo com a coleta de dados, durante as entrevistas, foram investigados os momentos considerados por esses sujeitos como os períodos em que eles mais se alimentavam. Nesse contexto, observou-se que o "estado emocional" foi apresentado como evento antecedente para o comportamento alimentar. Todos (15/15) os entrevistados descreveram esses comportamentos como estando diretamente ligados a sentimentos de ansiedade, tristeza, estresse, angústia, entre outros, como ilustram os relatos:

Eu acredito, assim, que a pessoa, quando ela é infeliz com alguma coisa, então ela releva, releva, releva por um tempo, mas, às vezes, lembra, ela anseia por alguma coisa, [...], aí bate aquela tristeza, aí começa a comer. $\mathrm{O}$ momento de tristeza às vezes leva a pessoa a comer (Aline).

Eu comia meio por ansiedade. Eu sou ansiosa, por isso que eu como. [...] Ou às vezes, quando eu tô agitada no meu serviço, quero terminar logo alguma coisa, [...] querendo resposta para alguma coisa (Jéssica).

Mais quando eu, assim... Ficava nervosa. Daí eu comia, comia. [...] Mais quando eu estava estressada, angustiada, discutia com meu marido, alguma coisa assim (Juliana).

Considerando o relato das entrevistadas sobre a forma como acontecia essa alimentação, novamente, verificou-se que todos descreveram que esta acontecia em grandes quantidades. Os participantes também especificaram que a ingestão alimentar hipercalórica ocorria em vários períodos ao longo do dia ou com intervalos espaçados entre uma refeição e outra, entretanto em grandes quantidades. Analisa-se que os intervalos elevados entre as refeições contribuem para o aumento da privação e, possivelmente, propicia que, ao se deparar com o alimento, o sujeito acabe ingerindo maiores quantidades. Como nos exemplos a seguir:

Acho que eu comia muito errado. E acho que foi por causa disso que eu engordei. [...] Muitas vezes e fora de horário. Tinha a geladeira toda hora, tinha fome toda hora. [...] Eu comia muita comida gordurosa, muito churrasco, muito refrigerante... Ao invés de pegar água, quando eu estava com sede, por exemplo, eu ia no refrigerante (Melissa).

Ah, eu comia desesperadamente, sem controle, né?! [...] Antes d'eu acabar de comer o prato, antes d'eu terminar, eu já estava repondo alimento no prato, né, e refrigerante por cima, ou água, ou suco, e comida, né, e logo após, é... Porque eu comia muito mesmo. Errado, né. Eu comia muita massa, muita fritura, tinha uma pressão muito alta de tanto que... Né (Aline). 
Eu nunca conseguia comer de 3 em 3 horas. Aí, quando eu comecei a fazer dieta e tudo e consegui de 3 em 3 horas, eu tinha resultado, mas era aquele resultado, como fala? Eu engordava, emagrecia, mas engordava. Efeito sanfona. Que você emagrece e engorda (Natália).

Em síntese, destaca-se que todos os entrevistados relataram a função do alimento como uma potente estratégia para lidar com as situações adversas, mesmo que, em alguns casos, estes não discriminassem claramente essas relações, ou as discriminassem verbalmente, mas não se comportassem sob controle do seu relato. Nesse sentido, analisa-se que, antes de ser descrito como um reforçador positivo, o alimento exercia função de reforçador negativo na vida do sujeito. Isto é, considerando a pouca quantidade de descrições em que os entrevistados relataram apenas a função reforçadora positiva do alimentar-se, mesmo sendo esta tão relacionada a alimentos saborosos, analisa-se seu valor secundário nesta relação.

\subsection{Operação estabelecedora para a realização da cirurgia}

A pessoa obesa, muitas vezes, pode entrar em contato com diferentes aversivos que influenciam em sua autoestima, em sua vida social, familiar, fisiológica e até mesmo profissional. Esses sujeitos são vistos de forma discriminatória, o que os leva a sentir certa desigualdade em relação às demais pessoas. Do ponto de vista social, é difícil para eles fazerem o que as outras pessoas fazem, como encontrar trabalho ou companhia, comprar roupas ou usar assentos em lugares públicos, como teatro e cinemas (Pinheiro apud Tinoco, Tinoco, El-Kadre, Tinoco, Crespo \& Haddad, 2002). Além do tratamento diferencial e discriminatório que é dispensado ao sujeito obeso, existem consequências biológicas atreladas a essa comorbidade, como o favorecimento de distúrbios metabólicos, circulatórios, respiratórios, entre outras enfermidades (Pinheiros apud Tinoco et al., 2002), o que também pode ser considerado aversivo. Assim, verificou-se no relato dos entrevistados que tais condiçōes (aversivas) bem como a privação de acesso a reforçadores foram as condições que favoreceram as entrevistadas a optarem pela realização da cirurgia, isto é, tais condições funcionaram como operações estabelecedoras.

Operações estabelecedoras são eventos ambientais que alteram a efetividade reforçadora de um estímulo, assim como evocam todo comportamento que, no passado, foi seguido por tal estímulo (Miguel, 2000). Dessa forma, o conceito parece descrever, em termos comportamentais, o que é usualmente chamado de motivação. Nesse caso, a operação estabelecedora funciona aumentando a efetividade da cirurgia como reforçadora e evocando toda a classe de respostas que seguem o estímulo cirurgia, como o seguimento das regras e o controle por todas as classes de reforços subsequentes ela. 
Como discutido, os aversivos de ser obeso produzem nos sujeitos sentimentos desagradáveis e motivação para buscar técnicas diversas e alcançar o emagrecimento desejado, incluindo dietas, medicação para redução de peso, ansiolíticos, entre outros. Entretanto, esgotadas as tentativas, muitos optam pela intervenção cirúrgica, acreditando que esta exige menos esforço de sua parte. Portanto o paciente que procura esse procedimento, de modo geral, já fez inúmeras tentativas de perda de peso em sua vida (Moliner \& Rabuske, 2008). Uma vez realizada a intervenção cirúrgica, são notórias para o sujeito as alterações corporais adquiridas, mostrando grande eficácia na redução de peso, diferente dos tratamentos anteriores supracitados que, por sua vez, demandam maior tempo e dedicação por parte do sujeito para alcançar o emagrecimento. Assim como observado no relato de Amanda:

Já tomei remédio, tentei fazer tratamento umas três vezes com o endocrinologista. Uma das vezes, eu passei mal, muito mal. Fiquei amarela, muito mal, mal mesmo, porque a medicação, ela tira toda a fome [...]. Aí eu larguei o tratamento de lado. E, uma outra vez, eu tomei uma medicação e comecei a passar mal dentro de casa, as vistas escurecendo [...]. Fiquei com as pernas bambas com um medo de morrer com a medicação pra emagrecer.

Dessa forma, considerando a definição de Miguel (2000), em que as operações estabelecedoras ou operaçōes motivacionais alteram a efetividade reforçadora de um estímulo, analisa-se que quanto mais privado de uma classe de reforçadores o sujeito estiver, mais esse reforçador controlará o comportamento desse sujeito quando estiver disponível.

Ou seja, quando o sujeito realiza a cirurgia, por mais invasiva que a intervenção possa ser ou por mais que esta exija dele mudanças drásticas em seus hábitos, sobretudo os alimentares, funcionará como uma importante fonte de reforço na vida desse sujeito. A partir dessa intervenção, ele espera alcançar reforçadores dos quais, outrora, ele era demasiadamente privado. Destarte, tornam-se inquestionáveis, para ele, os benefícios que a cirurgia produziu em sua vida, ainda que também tenha havido efeitos adversos. Diana relata, por exemplo: "Não me arrependo. Faria de novo e indico para qualquer gordo. Eu sei, porque eu sei o sofrimento de ser gordo". Sônia também avalia os resultados do procedimento: "Eu acho que o saldo é bem positivo. Fora essas vontades de comer, assim, fora o dumping que dá, que você tem que parar, dar uma esperada... Mas o meu benefício é muito mais". Amanda descreve os benefícios a sua autoestima: "Depois que eu fiz a cirurgia, eu fiquei magrinha mesmo, aí cortei o meu cabelo, fiz uma mudança radical mesmo, fiquei bem mais disposta [...]. Quando eu vou pra algum lugar, eu [...] vou toda arrumada, aí às pessoas: 'Hum, está arrebentando'”.

Entretanto os problemas podem surgir quando, após o emagrecimento desejado, esse paciente já não se encontra mais tão motivado a seguir as regras 
e instruções propostas pela equipe multidisciplinar e se mantém em sua vida a função que o alimento exercia.

\subsection{Regras, alimentação e pós-cirúrgico}

$\mathrm{Na}$ análise do comportamento, regras referem-se a um processo em que um falante descreve as contingências especificadoras, ou seja, as instruçôes a serem seguidas (regras) e as consequências que poderiam ocorrer caso não houvesse o seu seguimento (Reis, Teixeira \& Paracampo, 2005). No contexto da cirurgia, analisa-se que a equipe médica é identificada como falante que orientou os pacientes, sinalizando os novos comportamentos necessários após a operação, sobretudo no que se refere à nova dieta. Dessa forma, no que tange às novas regras aprendidas pelos pacientes, verificou-se, a partir do relato dos entrevistados, que, pelo menos inicialmente (nos primeiros meses de operado), umas das regras que se mostrou bastante frequente, na maioria das descrições, foi o comportamento de se alimentar em períodos de três em três horas e em pequenas quantidades. A participante Larissa, por exemplo, aponta: "Hoje eu como, de três em três horas, uma quantidade que eu acho agora normal para que uma pessoa se satisfaça". Relato semelhante ao da participante Jéssica: "Hoje minha alimentação é totalmente equilibrada, eu como de três em três horas, seguindo à risca ali, tudo certinho, as instruções da nutricionista”.

As consequências de não seguir as regras também são relatadas:

Eu ouço falar: "Ah, fulano fez redução, mais a pessoa só vomita". Existe gente assim. Sabe por que existe? Porque a pessoa não está olhando para ela. Gente, eu fiz redução, então eu tenho que me reeducar, não posso ficar cinco horas sem comer [...]. Gente tem que comer de duas em duas horas, senão você vai engasgar com o arroz (Sandra).

Entre outras consequências de não seguir as regras no pós-operatório está o dumping. De acordo com Fandiño, Benchimol, Coutinho e Appolinário (2004 apud Lemke \& Correia, 2008) a síndrome de dumping é ocasionada pela ingestão de carboidratos simples, ou seja, é a ingestão da quantidade de alimentos (líquidos ou sólidos) superiores ao habitual ou desproporcional à nova capacidade estomacal. Em seu trabalho, eles apontam que a síndrome surge como uma resposta fisiológica à desordem alimentar. $\mathrm{O}$ indivíduo apresenta náuseas, vômitos, rubor, dor epigástrica e sintomas de hipoglicemia. O que também foi verificado durante as entrevistas. Gabriela destaca: "Dá uma tonteira, parece que a pressão cai. Tem vezes que nem cerveja você pode tomar muito que dá, porque cerveja tem muito açúcar". Sandra também apontou as consequências fisiológicas que alguns alimentos desencadeiam: "Não me faz bem, porque a 
minha pressão abaixa e parece que eu vou morrer. É a pior sensação do mundo [...]. Você vai desfalecendo, vai ficando mole, fica toda formigando, meu cabelo fica todo molhado de tanto transpirar.

Dessa forma, torna-se possível analisar, com base nesses relatos, o dumping como uma modificação no comportamento respondente do organismo. $\mathrm{O}$ comportamento respondente é um tipo de interação em que uma resposta é emitida imediatamente após a apresentação do estímulo. Assim, podemse definir os comportamentos respondentes por suas respostas involuntárias (independentes da vontade do sujeito), que são controlados pelos eventos que precedem os estímulos eliciadores e não são aprendidos são universais (Moreira \& Medeiros, 2007). Nesse contexto, pelas descrições, verificou-se que o antecedente "cirurgia" diminui a capacidade de guardar e absorver os alimentos e, dessa forma, ao ingerir uma quantidade superior de alimentos ricos em açúcares e gorduras à suportada pelo "novo estômago", há como consequência a eliciação de respondentes aversivos. Assim como descrito pelos sujeitos.

Desse modo, considerando a amostra coletada, analisa-se que os sintomas vivenciados por esses sujeitos são tão desagradáveis que os estimulam a realizarem efetivamente as modificações necessárias no que tange à sua alimentação, deixando, muitas vezes, de fazer a ingestão desses grupos de alimentos para evitar os sintomas. Portanto, produzindo uma nova regra em seu repertório comportamental.

Além disso, a fim de evitar o contato com esses aversivos, observou-se nos relatos que, além de seguir as regras da equipe médica, alguns entrevistados também descreveram um forte controle por autorregras. Segundo Reis, Teixeira e Paracampo (2005), autorregras são descriçõos de contingências enunciadas pelo próprio indivíduo, formuladas a partir de sua exposição às contingências de reforço, sendo assim, exercendo controle sobre a resposta subsequente. Tendo em vista as falas dos entrevistados, verificou-se que, após a própria exposição à contingência de reforço, com base em suas experiências, os sujeitos descrevem uma regra em que ele possa controlar a resposta subsequente. Como ilustra alguns relatos: "Tem que comer direito e comer devagar" (Sandra). "Até pode me dar vontade, mas eu sempre compro um chiclete e mastigo. Eu sei que não aguento comer" (Diana). "Eu como churrasco, mas, a maioria das vezes, eu jogo a carne fora; eu só mastigo e jogo fora" (Larissa).

Dessa forma, percebe-se que a presença das regras e autorregras é fundamental para a manutenção e adequação ao novo comportamento alimentar. Sendo que comer devagar, mastigar a carne e jogá-la fora, comer de três em três horas e ingerir alimentos mais saudáveis são estratégias para se evitar aversivos, como 
síndrome de dumping ou engordar novamente. Além disso, ainda foi possível analisar que, para alguns pacientes, o seguimento das regras significa sucesso no pós-operatório, como descreve uma das entrevistadas a seguir e, portanto, tem importante valor reforçador, facilitando que tal aprendizado seja mais facilmente instalado no novo repertório comportamental do sujeito. A participante Karina explica: "Oh, uma coisa eu falo: você tem que seguir tim-tim por tim-tim do que o médico fala. Não abuse”.

No entanto, apesar de a maioria dos entrevistados terem sido expostos a regra do comer de três em três horas e em pequenas quantidades, bem como as seguilas, pelo menos inicialmente, notou-se que os participantes que tinham realizado a cirurgia havia um período maior demonstraram não ficarem mais sob controle dessas especificações. Note-se o relato a seguir, onde a entrevistada faz um comparativo entre seu comportamento logo depois de operada e no momento da entrevista (sete anos após a operação):

É, antes, era mais fácil. Hoje a gente está liberado, está comigo agora a responsabilidade. Sempre foi né, mas a gente joga um pouco em cima do médico né?! "Ele vai brigar comigo", então se pune. "Ah, não vou comer, vou sim, certinho." Então a pessoa está querendo aquele objetivo, está na busca daquele objetivo, daquele corpo magro, daquele corpo sarado. Aí, depois que passa, você não se importa tanto, já não é mais... Já não é mais a novidade (Amanda).

Ou seja, considerando a amostra pesquisada, bem como outros trabalhos que discutem o tema (Silva, 2012; Machado, Bruno, Ivan \& Monteiro, 2008), é possível analisar que, em uma contingência em que o paciente tem dificuldades em seguir as regras, mas a equipe multidisciplinar responsável pela cirurgia tem controle (ainda que parcial) de seu comportamento, sinalizando as orientações necessárias para manter seu repertório alimentar adequado, existe uma probabilidade maior de esse paciente continuar emagrecendo e, ou, manter o peso emagrecido. Entretanto se nota que, após o processo de emagrecimento e com o agente sinalizador (o médico/equipe multidisciplinar) ausente, a responsabilidade sobre esse comportamento passa para o próprio sujeito e, portanto, a regra pode se tornar menos presente. Nesse caso, se o alimento se mantém como um potente reforçador para o sujeito lidar com as situações adversas de sua vida, ele pode voltar a realizar uma dieta hipercalórica como fazia anteriormente. Isto posto, a provável consequência é o processo de reengorda.

Assim, destaca-se que, além de oferecer as orientações ao paciente, faz-se necessário que o acompanhamento terapêutico desenvolvido com esse sujeito seja realizado efetivamente, buscando conhecer sua história, seu processo de engorda, a função do alimentar-se em sua vida e as possibilidades de repertórios 
alternativos no manejo do pós-cirúrgico, a fim de que os pacientes possam desenvolver aquilo que Rachlin (1974) chama de resposta de compromisso. Isto é, emissão de comportamentos alternativos que possam competir com os comportamentos que devem ser evitados (por exemplo: como comer uma fruta em vez de um doce), ou ainda, emissão de respostas que reduzem o valor reforçador das consequências produzidas pelo comportamento alimentar (por exemplo: comer salada antes do prato principal para reduzir a quantidade de macarronada ingerida depois), e assim, aumentar os dados de sucesso do pósoperatório.

\subsection{Avaliação psicológica pré-operatório e acompanhamento terapêutico}

No contexto da cirurgia bariátrica, segundo Di Benedetto (2007), a função da avaliação psicológica é analisar as condições psicológicas e emocionais do paciente bem como apresentar a ele as inúmeras modificações que a cirurgia desencadeia, sobretudo no que tange às mudanças em seu repertório alimentar, social e psicológico e as implicaçôes relacionadas a elas.

Assim, o psicólogo é solicitado a elaborar um laudo, descrevendo as condições sociais e emocionais do paciente, a fim de propiciar diagnóstico e prognóstico para inferir aptidão ou não em relação ao procedimento bariátrico, podendo encaminhar o paciente à cirurgia ou aconselhar o acompanhamento psicoterápico antes de concretizar-se tal intervenção (Di Benedetto, 2007; Resolução CFP no 7/2003).

No entanto, considerando-se a amostra entrevistada, durante a análise do relato dos pacientes, verificou-se a falta de comprometimento de alguns profissionais na realização dessas avaliações bem como a incompatibilidade entre o que o Conselho Federal de Psicologia (Resolução CFP no 7/2003) argumenta como necessário e a forma como esse processo parece se concretizar. Os relatos seguintes são bastante ilustrativos:

Só fui duas vezes ao psicólogo. [...] Foi assim, foi pouco, mas, pra falar a verdade, não me acrescentou em nada, assim, em questão da cirurgia, porque a gente conversou mais coisa pessoal. Então eu peguei e falei: "Ah, eu vim aqui exclusivamente para o laudo, eu quero o laudo". E ela falou: "Então eu vou te dar o laudo". Aí eu fui em uma sessão, aí, na outra, ela me deu o laudo. Aí eu não fui mais (Amanda).

Fui no psicólogo, [...] uma única vez, porque tem que ter o laudo. Fui nela, falei o que eu queria e ela (psicóloga) falou: "Olha, você está muito certa no que você quer". Me deu o laudo que eu precisava. Pronto. E não fui nunca mais no psicólogo (Luíza). 
Larissa também descreveu sua experiência: "Fui só na palestra. Depois a gente volta pra esse psicólogo nos dar um laudo. Mas foi um contato de dez minutos".

Assim, apesar de a etapa da avaliação psicológica ser um critério obrigatório para a submissão a cirurgia, em muitos casos, como verificado no relato dos entrevistados, ela é negligenciada ou realizada de modo pouco consistente. De acordo com a Resolução CFP no 7/2003, o processo de avaliação psicológica deve considerar determinações históricas, sociais, econômicas e políticas, sendo os mesmos elementos constitutivos do sujeito. Portanto avaliações realizadas de forma muito breve e que não levam em conta as diferentes dimensões do paciente e dos contextos em que ele está inserido tornam o laudo pouco eficaz como preditor de aptidão ou não ao procedimento.

Além disso, considerando a amostra pesquisada, analisa-se que as variáveis necessárias para realizar a intervenção não são esclarecidas pela equipe médica aos pacientes, bem como há, por parte destes, um grande desconhecimento a respeito do papel do psicólogo no contexto da cirurgia, deixando-os sem uma noção clara dos motivos pelos quais esse profissional aprovou a intervenção para o seu caso. Aspectos que se tornam evidentes, pelos relatos das participantes: "Ah não eu fui rápida, a minha mente é boa" (Gabriela). "Deu certo comigo, porque eu já tinha uma cabeça pronta, já tinha, mais ou menos... Mastigando isso" (Larissa). "Eu só fiz uma consulta antes [...] para ver se tinha ou não algum problema psicológico. [...] E no pós, eu só tive algumas consultas, que foram assim, para avaliar como eu estava. Então ele percebeu que minha cabeça está maravilhosa" (Juliana).

De outro modo, também se observou na descrição dos sujeitos o papel do psicólogo como sendo aquele de caráter informativo, ou seja, identificado por sua função em apresentar ao paciente o procedimento, avaliar seu conhecimento a respeito das etapas do processo, analisar sua disposição para submeter-se à cirurgia e verificar se há presença de algum transtorno psicológico impeditivo. Mais uma vez, indicando o fato de que, no pré-operatório, não são avaliadas as funçôes do comer para o candidato e as possibilidades de manejo dessa função. Além disso, também não foram identificados relatos que apontassem o desenvolvimento de repertórios alternativos que auxiliassem os pacientes na adaptação do pós-cirúrgico. Entretanto se verifica-se, pela fala dos entrevistados, que, mesmo não discriminando durante o processo de avaliação a necessidade de um acompanhamento terapêutico mais consisten te, posteriormente alguns pacientes reconhecem essa necessidade, como descrito pela participante Natália: 
Não faço acompanhamento. Mas eu preciso muito. Sabe quando você olha e você não se vê no corpo que você está? [...] Eu me olho no espelho e falo: "Cara, não! Essa pessoa não sou eu”. [...] Só que, agora, é uma coisa assim, eu estou desesperada, eu sei que eu preciso de um psicólogo (Natália).

Dessa forma, o acompanhamento terapêutico antes e após a cirurgia se torna fundamental. Durante esse processo, o psicólogo pode trabalhar questões como: o autoconhecimento do paciente, suas motivaçóes para buscar a intervenção, esclarecer possíveis dúvidas procedimento e suas consequências a curto e longo prazo, os esforços que ele deverá empreender para alcançar o sucesso póscirúrgico, o desenvolvimento de novos repertórios e, ou, repertórios alternativos ao comportamento alimentar, identificação de questões emocionais a serem trabalhadas em virtude ou não da obesidade, entre outras.

Portanto o psicólogo deve observar as questões éticas que embasam seu trabalho quando emitem um documento tornando apto um paciente que não foi acompanhado integralmente no processo de avaliação psicológica. Tal procedimento a ser realizado com cautela e de modo consistente, envolvendo diferentes facetas durante a avaliação, bem como um acompanhamento efetivo desse sujeito antes, durante e depois da intervenção são fundamentais para que sejam alcançados resultados positivos no pós-cirúrgico, tanto a curto quanto em longo prazo.

\subsection{Repertórios alternativos: uma possível solução}

De acordo com Skinner (1974), repertório comportamental refere-se àquilo que uma pessoa é capaz de fazer, dadas as circunstâncias adequadas. Portanto se trata de uma disposição para comportar-se de modo diferenciado em determinadas situações, considerando as experiências de vida do sujeito e o modo como elas o modelaram. Assim, quando se trata de novos repertórios comportamentais, após a intervenção cirúrgica bariátrica, discute-se a necessidade de desenvolver comportamentos funcionalmente equivalentes para alcançar os reforçadores que, anteriormente, eram produzidos pelo comportamento alimentar. Nesse sentido, foi investigado, durante as entrevistas, se os sujeitos têm novos repertórios ou usam repertórios alternativos para lidar com o pós-cirúrgico e quais são esses repertórios.

Considerando a amostra pesquisada, verificou-se que grande parte dos entrevistados (6 em 15) nunca havia pensado sobre o tema, assim como descreve a participante Natália: "É... Acho que não parei ainda para pensar sobre isso. No lugar, no lugar não. E, quando eu tô com muita vontade, eu como. Mas, depois a gente tem que compensar né”. 
Ademais, no que tange a outras classes de repostas referentes aos repertórios alternativos, analisou-se, com base na descrição das entrevistadas, repertórios relatados por elas como alternativos, mas que não parecem equivalentes ao reforço produzido, outrora, pelo alimento. Como nas descriçôes que se seguem: "Olhar vitrines. [...] Num sei. Num sei se dá para comparar. Eu fico estressada e vou caminhar, sabe como? Mas, sei que me deixa mais calma" (Melissa). "Eu xingo muito né. Me aborreceu, era palavrão, era... [risos]... Vou falando!" (Karina). "Eu sei que, se eu não me ligar, eu fico comendo. Mas se eu como assim, eu não aguento. Agora, eu sempre compro um chicletinho sem açúcar e fico mastigando" (Diana).

De outro modo, verificaram-se, pelo relato de três pacientes, repertórios que podem ser alternativas adaptativas eficazes para produzir reforçadores equivalentes aos produzidos pelo alimento como a prática de esportes, caminhadas e exercícios físicos: "Tenho disposição para atividade física, não fico sem atividade física... Faço hidroginástica e faço caminhada, eu vou alternando. E hoje é muito diferente, a minha disposição para a minha casa é outra" (Larissa). "Ah, eu vou caminhar. [...] E, nesses dias, eu fui pra academia assim, pra me inscrever lá, eu tô toda animada" (Natália). "Agora faço exercício. Na verdade, eu já fazia antes, eu só intensifiquei um pouquinho. Mas é diferente, porque tem que ter uma manutenção, senão você volta de novo" (Simone).

Verifica-se que a prática de tais atividades libera hormônios, como endorfina, produzidos durante e após sua execução, regulando as emoções e reduzindo o estresse e a ansiedade (Mello, Boscolo, Esteves \& Tufik, 2005). Dessa forma, analisa-se que as atividades físicas podem funcionar como alternativas saudáveis ao comportamento alimentar inadequado, uma vez que, biologicamente, auxiliam a regular as emoções relatadas como antecedentes à emissão desse repertório. Além disso, considerando o gasto energético que ocorre durante a prática dessas atividades, torna-se possível ponderar, também, sua contribuição na perda/manutenção de peso do sujeito operado. Contudo, assim como verificado, poucos foram os casos em que esses repertórios se desenvolveram.

Destarte, uma das principais implicações no que tange à falta de comportamentos alternativos e uma das que mais têm aumentando sua incidência na literatura refere-se às consequências negativas da cirurgia na vida sujeito, depois de um período maior em que esta foi realizada. Isto é, além da possível e provável reengorda, considerando a função do alimentar-se na vida do sujeito, o impedimento fisiológico de manter seu comportamento alimentar hipercalórico e a falta de repertórios alternativos para lidar com as novas contingências de reforço presentes, verificou-se na literatura que é provável que novos repertórios de esquiva sejam selecionados pelo paciente, principalmente aqueles ligados a 
mudanças diretas de estados corporais, como no uso de álcool e drogas (King, Chen, Mitchell, Kalarchian, Steffen, Engel, . . . \& Yanovski, 2012; Agência Nacional de Vigilância Sanitária, 2008). Nesses casos, o álcool e as drogas podem oferecer o acesso ao reforço que a comida antes propiciava, logo o repertório de uso de tais substâncias pode ser selecionado.

Em última análise, apesar de também não ter sido identificado no relato dos entrevistados, outros trabalhos chamam a atenção para o fato de esse sujeito, muitas vezes, eliminar o contato com o aversivo, com base numa classe extrema de reforço negativo: o suicídio (Floresi, Machado \& Soares, 2009; Omalu, Ives, Buhari, Lindner, Schauer, Wecht \& Kuller, 2005; Tindle, Omalu, Courcoulas, Marcus, Martelos \& Kuller, 2010). Verificou-se nessas pesquisas que, principalmente no primeiro ano após a cirurgia, há uma maior prevalência de suicídio entre os pacientes. Entre as causas relacionadas à sua ocorrência estão os estressores produzidos tanto na esfera pessoal quanto produto das questóes sociais, contendo diversas facetas, tais como a pressão social para a rápida perda de peso, a falta de repertório para lidar com situações de exposição social, a dificuldade em lidar com as mudanças físicas consequentes da cirurgia, entre outros.

Assim, considerando o aumento do número de casos que tem apresentado dados negativos no pós-cirúrgico, analisa-se a importância do desenvolvimento de repertórios alternativos, anteriores e, ou, posteriores à intervenção, durante um processo de acompanhamento terapêutico com esses pacientes. Além disso, uma avaliação psicológica consistente, que privilegie diferentes aspectos de vida do sujeito, pode alterar os dados de insucesso do pós-operatório, diminuindo alguns possíveis e prováveis riscos pós-cirúrgicos (episódios de hiperfagia, depressão, alcoolismo, etc.), bem como desenvolvendo repertórios alternativos mais adaptativos.

\section{CONSIDERAÇÕES FINAIS}

Tendo em vista a função do alimentar-se na vida do obeso, analisou-se que, após a intervenção cirúrgica bariátrica, o sujeito estará mecanicamente impedido de manter seu comportamento alimentar hipercalórico. Portanto se destaca a importância dos repertórios alternativos para que o paciente possa manejar o póscirúrgico, diminuir os dados relacionados às consequências adversas da cirurgia e adaptar-se com sucesso à sua nova condição. Processo que se tornaria possível, principalmente, a partir da avaliação psicológica que antecede a cirurgia, na qual podem ser analisadas as diferentes variáveis e contingências a que o sujeito obeso está exposto e, então, considerada a necessidade ou não do desenvolvimento de 
tais repertórios com o paciente e um acompanhamento terapêutico mais efetivo.

Entretanto, considerando a amostra pesquisada, verificou-se que, apesar da avaliação psicológica ser um requisito obrigatório para que o candidato à cirurgia esteja apto ao procedimento, os pacientes entrevistados relataram que esse processo tinha, em média, duração de apenas uma sessão, com a função de apenas torná-los, parcialmente, conscientes das mudanças que a cirurgia produziria em sua vida e as regras e procedimentos que deveriam seguir para que minimamente fosse garantido o sucesso do pós-operatório. Com base nesses dados, analisa-se que não há uma preocupação clara por parte de alguns profissionais da Psicologia com os riscos comportamentais e psicológicos que podem ser produzidos a partir da cirurgia, bem como não existe uma avaliação da função do comportamento alimentar na vida do sujeito, antes do procedimento.

Desse modo, uma consideração relevante, com base no exposto, reside no fato de que os sujeitos operados em período mais recente descrevem seguir as orientaçôes médicas e manterem-se vigilantes com a nova rotina, desenvolvendo regras e autorregras e destacando, sobretudo, os reforçadores aos quais tiveram/ têm acesso a partir da cirurgia, tornando-se para eles inquestionáveis esses benefícios. Contudo, ao observar o relato dos pacientes que já haviam realizado a cirurgia a um período de tempo maior (a partir de dois anos de operado), destaca-se o fato de que estes estavam menos sob controle da regra e mais sensíveis à contingência atual. Desse modo, relataram situações nas quais ainda se deparavam com a inabilidade para lidar com algumas contingências e a falta de outras estratégias de controle emocional, voltando a buscar no comportamento alimentar respostas de fuga-esquiva.

Além disso, considerando a literatura consultada, muitas vezes, há, por parte desses pacientes, o desenvolvimento de repertórios alternativos problemáticos que produzem reforço equivalente aos produzidos pelo comportamento alimentar como: o uso de álcool e drogas. Em uma última análise, fica coerente a afirmação de alguns autores (Fandino et al., 2004; Floresci, Machado \& Soares, 2009) que também apontam para um comportamento extremo desta classe de fuga-esquiva: o suicídio. Entretanto se destaca que esse dado não foi coletado dentro da amostra pesquisada.

Assim, tendo em vista os relatos analisados, discute-se que as regras são importantes estímulos discriminativos, nesse contexto, exercendo a função de orientar o paciente a respeito dos novos comportamentos que deve emitir. Contudo, além de oferecer as orientações e regras ao paciente, faz-se necessário que o acompanhamento terapêutico desenvolvido com esses pacientes, por profissionais da Psicologia, seja realizado de modo efetivo, buscando conhecer 
sua história, seu processo de engorda, a função do alimentar-se em sua vida e as possibilidades de outros repertórios menos problemáticos no manejo do póscirúrgico, a fim de que os pacientes possam desenvolver respostas de compromisso eficazes e, assim, seja possível diminuir os dados de insucesso no pós-cirúrgico, auxiliando o paciente a lidar com sua nova condição.

Diante do exposto, para diminuir o sofrimento do paciente e fazer cumprir toda expectativa que se coloca em tal cirurgia, ou seja, ganhar qualidade de vida, de modo geral e em diferentes âmbitos, é que endossamos a necessidade de uma avaliação psicológica cuidadosa bem como um acompanhamento terapêutico mais sistemático. Dessa forma, acredita-se que novos estudos devem ser empreendidos para que se alcance tal objetivo e seja possível oferecer melhor atendimento aos pacientes candidatos à cirurgia bariátrica, diminuindo os efeitos adversos do pós-operatório e contribuindo com a saúde física e psicológica dessas pessoas. 


\section{REFERÊNCIAS}

Agência Nacional de Vigilância Sanitária [Anvisa] (2008). Cirurgia bariátrica no tratamento da obesidade mórbida. Boletim Brasileiro de Avaliação de Tecnologias em Saúde, 5, 1-11.

Benedetto, C. (2007). Avaliação psicológica na cirurgia bariátrica: reflexões pertinentes. In Anais, 3 Congresso Internacional de Psicologia e 9 Semana de Psicologia (pp. 1-5). Maringá. Maringá: Universidade Estadual de Maringá.

Cardoso, L. de O.; Costa, M. F. L.; Menezes, L. C. M.; Magalhães, C. C. \& Pires, A. V. C. Obesidade e cirurgia bariátrica: significados para o ex-obeso. (no prelo).

Ehrenbrink, P. P., Pinto, E. E. P. \& Prando, F. L. (2009). Um novo olhar sobre a cirurgia bariátrica e os transtornos alimentares. Psicologia Hospitalar, 7 (1), 88-105.

Fandiño, J., Benchiolmol, A. K., Coutinho, W. F. \& Appolinário, J. C. (2004). Cirurgia bariátrica: aspectos clínico-cirúrgicos e psiquiátricos. Revista de Psiquiatria do Rio Grande do Sul, 26, (1), 47-51.

Felippe, F. M. (2003). O peso da obesidade Social. Revista Virtual Textos \& Contextos, 2, 1-12.

Francischi, R. P. P., Pereira, L. O., Freitas, C. S., Klopfer, M., Santos, R. C., Vieira, P. \& Lancha Júnior, A. H. (2000). Obesidade: atualização sobre sua etiologia, morbidade e tratamento. Revista de Nutrição, 13 (1), 17-28.

Floresi, A. C. F., Machado, B. H. \& Soares, S. M. de S. R. (2009). Cirurgia bariátrica e risco de suicídio. Revista de Psiquiatria Clínica, 36 (2), 83-84.

King, W. C.; Chen, J. Y., Mitchell, J. E., Kalarchian, M. A., Steffen, K. J., Engel, S. G., ... Yanovski, S. Z. (2012). Prevalence of alcohol use disorders before and after bariatric surgery. JAMA, 307 (23), 2516-2525.

Lemke, G. M. M. N. \& Correia, J. S. C. (2008). Tratamento cirúrgico da obesidade e a ocorrência da síndrome de dumping. Revista Saber Cientifico, 1 (1), 176-193.

Martin, G. \& Pear, J. (2009). Modificação do comportamento. (8a Ed.). São Paulo: Roca. 
Machado, C. E., Bruno, Z., Ivan, C. \& Monteiro, M. (2008). Compulsão alimentar antes e após a cirurgia bariátrica. ABCD. Arquivos Brasileiros de Cirurgia Digestiva, 21 (4), 185-191.

Mello, M. T. de, Boscolo, R. A., Esteves, A. M. \& Tufik, S. (2005). O exercício físico e os aspectos psicobiológicos. Revista Brasileira de Medicina do Esporte, 11 (3), 203-207.

Meyer, S. B. (2008). Functional Analysis of Eating Disorders. Journal of Behavior Analysis in Health, Sports, Fitness and Medicine, 1 (1), 26-33.

Miguel, C. F. (2000). O conceito de operação estabelecedora na análise do comportamento. Psicologia: Teoria e Pesquisa, 16 (3), 259-267.

Moliner, J. de \& Rabuske, M. M. (2008). Fatores biopsicossociais envolvidos na decisão de realização da cirurgia bariátrica. Psicologia: Teoria e Prática, 10 (2), 44-60.

Moreira, B. M. \& Medeiros, C. A. (2007). Princípios básicos de análise do comportamento. Porto Alegre: Artmed.

Netto, C. A. (2002). Psicobiologia do comportamento alimentar. In Nunes, M. A., Appolinário, J. C., Galvão, A. L. \& Coutinho, W. Transtornos alimentares e obesidade. (pp. 47-53). Porto Alegre: Artmed.

Omalu, B. I., Ives, D. G., Buhari, A. M., Lindner, J. L., Schauer, P. R., Wecht, C. H. \& Kuller, L. H. (2007). Death rates and causes of death after bariatric surgery for Pennsylvania residents, 1995 to 2004. American Medical Association, 142 (10), 923-8.

Rachlin, H. (1974). Self-control. Behaviorism, 2, 94-107.

Reis, A. A. dos, Teixeira, E. R. da \& Paracampo, C. C. P. (2005). Autorregras como variáveis facilitadoras na emissão de comportamentos autocontrolados: o exemplo do comportamento alimentar. Revista Interação em Psicologia, 9 (1), 57-64.

Resolução CFP no 7/2003. (2003). Manual de elaboração de documentos escritos produzidos pelo psicólogo, decorrentes da avaliação psicológica. Institui o Manual de Elaboração de Documentos Escritos produzidos pelo psicólogo, decorrentes de avaliação psicológica e revoga a Resolução CFP o 17/2002. Brasília: CFP. 
Silva, F. B. L. (2012). Fatores associados ao reganho de peso após 24 meses de gastroplastia redutora em Y-de-Roux. (Dissertação de Mestrado). Faculdade de Ciências da Saúde, Programa de Pós-Graduação em Nutrição Humana, Universidade de Brasília, Brasília.

Skinner, B. F. (1974). Sobre o behaviorismo. (12a Ed.). São Paulo: Cultrix.

Skinner, B. F. (2000). Ciência e comportamento humano. (11a Ed.). São Paulo: Martins Fontes.

Sociedade Brasileira de Cirurgia Bariátrica e Metabólica (2013). Tratamento cirúrgico: quem pode fazer? São Paulo: SBCBM.

Tindle, H., Omalu, B., Courcoulas, A., Marcus, M., Martelos, J. \& Kuller, L. H. (2010). Risk of suicide after long-term follow-up from bariatric surgery. The American Journal of Medicine, 123(11), 1036-1042.

Tinoco, R. C., Tinoco, A. C. A., El-Kadre, L. J., Tinoco, L. A., Crespo, L. F. \& Haddad, M. O. (2002). Cirurgia da obesidade mórbida por videolaparoscopia. Revista do Colégio Brasileiro de Cirurgioes, 29(3), 138-144.

Vale, A. M. O. \& Elias, L. R. (2011). Transtornos alimentares: uma perspectiva analítico-comportamental. Revista brasileira de terapia comportamental $e$ cognitiva, 13(1), 52-70.

Vieira, G. C. (2006). Variação no acesso a reforçadores entre grandes obesos antes e depois de submissão a gastroplastia. (Dissertação de Mestrado). Universidade de Brasília, Instituto de Psicologia, Brasília.

World Health Organization. (2008). Obesity and overweight. Geneva: World Health Organization. Recuperado a partir de http://www.who.int/news-room/ fact-sheets/detail/obesity-and-overweight 